dr. sci. Hatidže Burnić, docent

Univerzitet u Bihaću

Islamski pedagoški fakultet

E-mail: hatidre_b@botmail.com

dipl. iur. Anita Ramulić Mujkić

Univerzitet u Bihaću

Islamski pedagoški fakultet

E-mail:anita_ramulic@yahoo.com

\title{
KOMPARATIVNA PRAGMATIČKA ANALIZA UVREDE I KLEVETE I NJIHOVE PRAVNE REFLEKSIJE
}

\section{Sažetak}

Čast i ugled ličnosti predstavljaju jednu od značajnih društvenih vrijednosti. Ukoliko onemogućimo pojedincima da štite svoje lično dostojanstvo i ugled, bitno zadiremo u osnovna ljudska prava. Bosna i Hercegovina je izvršila dekriminalizaciju klevete i uvrede putem donošenja Zakon o kleveti. Osnovne osobine krivičnih djela protiv časti i ugleda određene su krivičnim zakonima početkom XIX vijeka kada su utvrdene jasnije granice između klevete i uvrede. Naime, odredeni dio teoretičara smatra da je kažnjavanje za klevetu i uvredu na ovaj način necivilizirano i nedemokratsko ponašanje koje ugrožava slobodu medija i u krajnjoj instanci narušava osnovna ljudska prava i slobode. Stoga se države trebaju približiti demokratskim standardima putem dekriminalizacije klevete $i$ uvrede. Upravo iz gore pomenutog razloga u radu se obraduje komparativna analiza zakonodavstva u domenu klevete i uvrede kao i njene pravne refleksije. Nadalje u praksi postoje veliki problemi prilikom dokazivanja uvrede i klevete. Stoga je nužno pristupiti pragmatičkoj analizi upotrijebljenih termina u kontekstu klevete. Naime, tuženi se može braniti konstatacijom da "to nije mislio na takav način“, odnosno, da svojom izjavom nije namjeravao postići navedenu pravnu posljedicu pa smo stoga pristupili utvrdivanju pragmatičnih ciljeva uvrede i klevete i njihove pravne refleksije. 
Ključne riječi: uvreda, kleveta, dekriminalizacija, komparativna analiza, pragmatična analiza.

\section{UVODNA KONTEKSTUALIZACIJA PROBLEMA}

Pravni instituti „kleveta“ i „uvreda“ trebaju isključivo biti u domenu građansko-pravne odgovornosti, odnosno, suđenje za klevetu i uvredu treba dopustiti isključivo u (civilnim) parničnim postupcima upravo zbog dokaznog postupka. $\mathrm{U}$ radu se obrađuje komparativna i pragmatička analiza navedenih instituta i njihove pravne refleksije.

\section{POJMOVNO ODREĐENJE „UVREDE“ I „KLEVETE“}

Čast i ugled predstavljaju dvije kategorije čiju zaštitu ne treba dovoditi u pitanje. One su priznate u skoro svim zakonodavstvima i izuzetno su važni postulati kako s moralnog, tako i s pravnog gledišta. Obilježje osnovnih krivičnih djela protiv časti preciznije su određene u krivičnim zakonima početkom XIX stoljeća kada su utvrđene jasnije granice između klevete i uvrede.

Prilikom pojmovnog određenja časti i ugleda, u prvi plan želimo da istaknemo da se svaka ljudska individua odlikuje ovim kategorijama koje su sastavni, neodvojivi dio njene ličnosti. Čast se najčešće definiše kao skup nematerijalnih vrijednosti koje čovjek posjeduje kao ljudsko biće i kao pripadnik određene društvene zajednice. Ona se stiče samim rođenjem. O ugledu se govori kao o drugoj strani časti. To je definicija ugleda koju danas susrećemo kod mnogih autora. $\mathrm{Na}$ ovaj način određene, čast i ugled predstavljaju neodvojivu kategoriju koja se može posmatrati ne samo sa krivično-pravnog stanovišta već i sa filološkog, sociološkog, psihološkog, filozofskog i drugih aspekata. ${ }^{1}$

\section{PRAGMATIČKA ANALIZA "UVREDE" I "KLEVETE"}

Pragmatika se bavi proučavanjem značenja koje govornik (ili pisac) prenosi slušatelju (ili čitatelju) koji ga potom interpretira. Ona se, dakle, više bavi analiziranjem onoga što ljudi zapravo žele reći svojim

\footnotetext{
${ }^{1}$ Opširnije o problematici pojmovnog određenja uvrede i klevete te definiranju pomenutih instituta vidjeti u: Mehmed Halilović i Amer Džihana, Medijsko pravo u Bosni i Hercegovini, Sarajevo, 2012, str. 34-75
} 
iskazima nego samim značenjem riječi ili fraza koje pritom upotrebljavaju. Pragmatika je proučavanje značenja koje govornik izriče. Jedna od tradicionalnih podjela unutar jezičke analize suprotstavlja pragmatiku sa sintaksom i semantikom. Sintaksa je proučavanje odnosa između jezičkih oblika, kako se oni nižu u veće jedinice i koji su nizovi. Takvo proučavanje obično ne uzima u obzir stvarno okruženje ili same govornike. Semantika je proučavanje odnosa između jezičkih oblika i jedinica u svijetu, to jest, doslovno: kako se riječi povezuju sa stvarima. Semantička analiza također pokušava opisati odnose između verbalnih opisa i činjeničnih stanja u svijetu kao tačne (istinite) ili netačne, bez obzira na autora tih verbalnih opisa. $^{2}$

Postupajući po gore pomenutom modelu to, ustvari, podrazumijeva upotrebu lekseme u konkretnom jezičkom i vanjezičkom kontekstu. Nakon toga dolaze do izražaja vanjezička dimenzija dekodiranja i tekstualno značenje, u području pragmatike, a zatim do rješenja svih slučajeva dvoznačnosti.

\subsection{Pragmatička i pravna analiza slučajeva: "Poruke iz učionice"}

U nastavku izlaganja prilaže se nekoliko primjera pod nazivom: "Poruke iz učinoce" gdje se nastoji ukazati na pragmatičku stranu upotrijebljenih termina koji direktno impliciraju na uvredu ili klevetu što u krajnjoj instanci može predstavljati pravnu okolnost u određenom pravnom postupku koji se vodi zbog "kelvete" i "uvrede". Dakle, pragmatička analiza upotrijebljenih termina izuzetno je važna u toku parničnog postupka koji se vodi zbog slučajeva uvrede i klevete jer u toku svjedočenja ili vještačenja pred sudom pragamtička analiza upotrijebljenih termina može biti od ključne važnosti za tužioca ili tuženog prilikom odmjeravanja novčane kazne zbog pretrpljene štete, naprimjer "narušavanja poslovnog ugleda". U nastavku rada prilaže se kratak pregled mogućih situacija.

${ }^{2}$ George Yule, Definicije i pozadina pragmatike te deiksija i udaljenost, Oxford University Press, 1996, str. 89 


\begin{tabular}{|c|c|}
\hline Pragmatička analiza & Pravna analiza \\
\hline 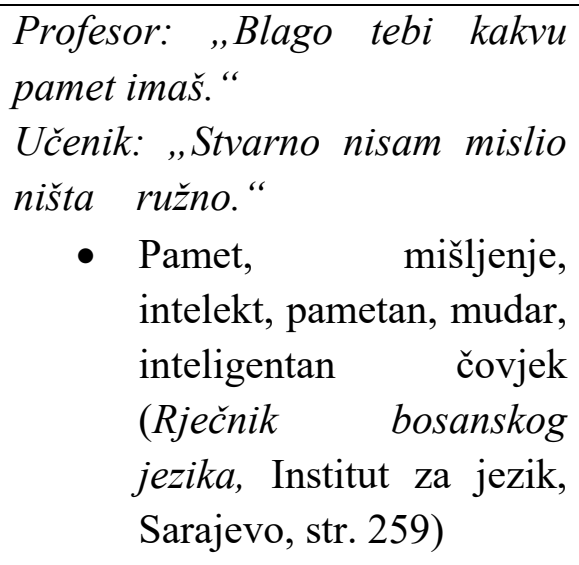 & $\begin{array}{l}\text { Profesor: „Blago tebi kakvu } \\
\text { pamet imaš. “ } \\
\text { Učenik: „, Stvarno nisam mislio } \\
\text { ništa ružno. “ } \\
\text { - Pamet, mišljenje, } \\
\text { intelekt, pametan, mudar, } \\
\text { inteligentan čovjek } \\
\text { (Rječnik bosanskog } \\
\text { jezika, Institut za jezik, } \\
\text { Sarajevo, str. 259) }\end{array}$ \\
\hline $\begin{array}{l}\text { Pragmatička analiza: } \\
\text { - Pozitivno tumačenje } \\
\text { Profesor: „Odlično si obavio } \\
\text { zadatak, jako si pametan.“ } \\
\text { - Negativno tumačenje } \\
\text { Profesor: „Jako si loše uradio } \\
\text { zadatak, nisi inteligentan“ }\end{array}$ & $\begin{array}{l}\text { Pravna analiza: } \\
\text { - Negativno tumačenje } \\
\text { Profesor: ,Jako si loše } \\
\text { uradio zadatak, nisi } \\
\text { inteligentan.“ } \\
\text { - Pravna refleksija: uvreda } \\
\text { prema čl. 200, Zakona o } \\
\text { obligacionim odnosima } \\
\text { lex generalni) }\end{array}$ \\
\hline $\begin{array}{l}\text { Profesor: „Vi ste svi kao fikusi.“ } \\
\text { Učenici: „Nije istina vidite da } \\
\text { smo aktivni." } \\
\text { • Fikus - vrsta sobne, kućne } \\
\text { biljke (Rječnik bosanskog } \\
\text { jezika, Institut za jezik, } \\
\text { Sarajevo, str. 79) }\end{array}$ & $\begin{array}{l}\text { Profesor: „Vi ste svi kao fikusi.“ } \\
\text { Učenici: „Nije istina vidite da } \\
\text { smo aktivni.“" } \\
\text { - Fikus - vrsta sobne, kućne biljke } \\
\text { (Rječnik bosanskog jezika, } \\
\text { Institut za jezik, Sarajevo, str. 79) }\end{array}$ \\
\hline $\begin{array}{l}\text { Pragmatička analiza: } \\
\text { - Pozitivno tumačenje } \\
\text { Profesor: „Jako ste mirni i } \\
\text { poslušni. Super je raditi s } \\
\text { vama.“ }\end{array}$ & $\begin{array}{l}\text { Pravna analiza: } \\
\text { - Negativno tumačenje } \\
\text { (uvreda) Profesor: } \\
\text { „Vi ste pasivni, }\end{array}$ \\
\hline
\end{tabular}




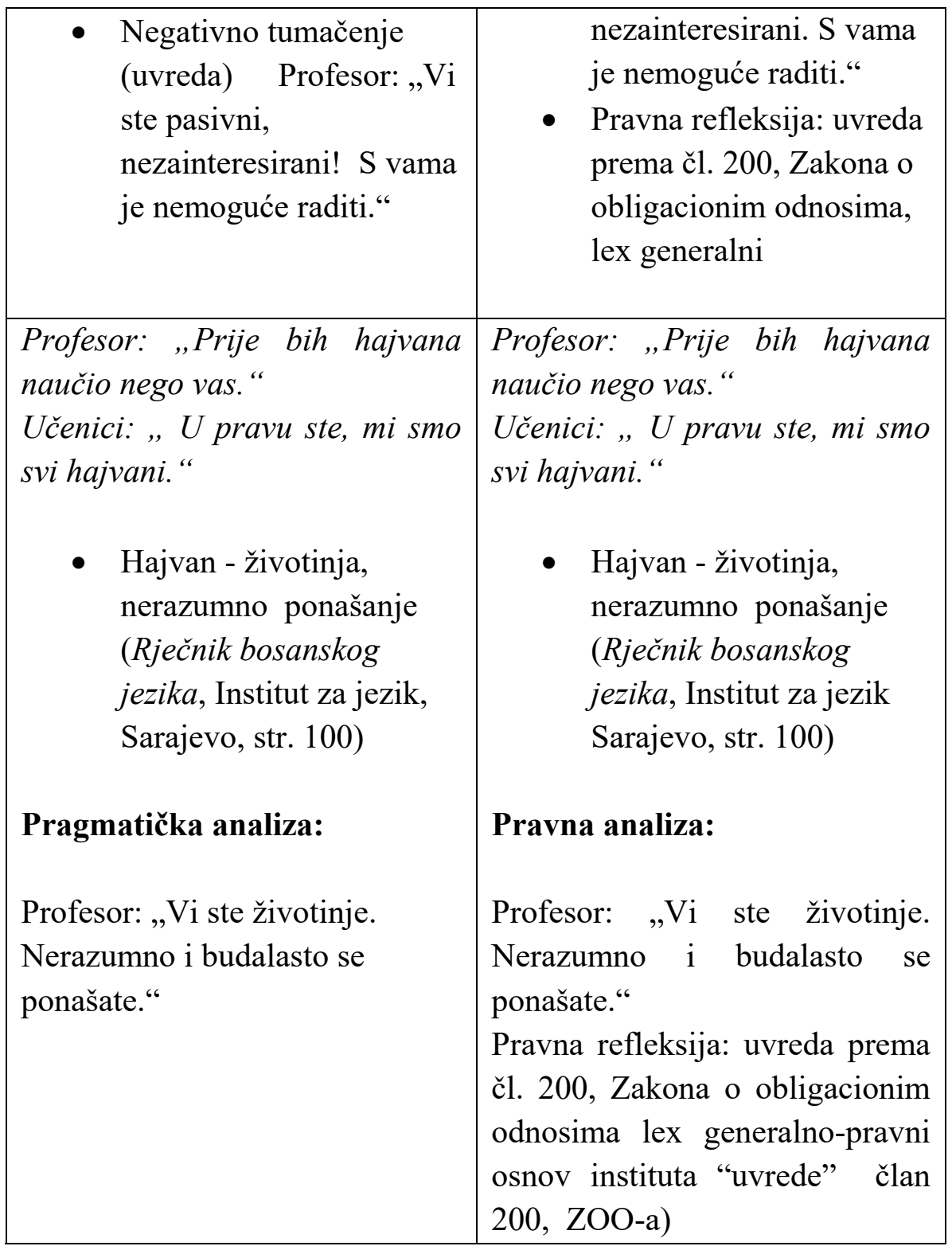

U članu 200 ZOO-a decidno se navodi: “(1) Za pretrpljene fizičke bolove, za pretrpljene duševne bolove zbog umanjenja životne aktivnosti, naruženosti, povrede ugleda, časti, slobode ili prava ličnosti, smrti bliskog lica kao i za strah sud će, ako nađe da okolnosti slučaja, a naročito jačina bolova i straha i njihovo trajanje to opravdava, dosuditi 
pravičnu novčanu naknadu nezavisno od naknade materijalne štete kao i u njenom odsustvu.

(2) Prilikom odlučivanja o zahtjevu za naknadu nematerijalne štete, kao i o visini njene naknade, sud će voditi računa o značaju povrijeđenog dobra i cilju kome služi ta naknada, ali i o tome da se njome ne pogoduje težnjama koje nisu spojive sa njenom prirodom i društvenom svrhom."3

Naknada za nematerijalnu štetu se može priznati samo za onu nematerijalnu štetu koju, kao takvu priznaje zakon, a ne za bilo koju nematerijalnu štetu. Pod nematerijalnom štetom u smislu Zakona o obligacionim odnosima podrazumjevaju se fizička bol, psihička bol i strah. Ista šteta se vezuje (po prirodi stvari) za fizičko lice. Naime, povreda dobrog poslovnog ugleda tužioca sama po sebi ne može dovesti do novčane naknade na ime nematerijalne štete, zato što se posljedice te povrede ne manifestuju u jednom od pravno priznatih vidova nematerijalne štete. Iz povrede poslovne reputacije pravnog lica može proisteći samo imovinska šteta u smislu poljuljanog ugleda koji treba povratiti odgovarajućim sredstvima građansko-pravne zaštite. Stoga je u dokaznom postupku od velike važnosti, prilikom svjedočenja, pragmatička analiza „korištnih“ termina kojim je tužiocu narušen poslovni ugled. ${ }^{4}$

\section{KLEVETA U EVROPSKIM ZAKONIMA - KOMPARATIVNA ANALIZA}

U ovom dijelu izlaganja prezentirat će se zakonska regulativa klevete $\mathrm{i}$ uvrede $\mathrm{u}$ evropskim državama, s posebnim osvrtom na zemlje Jugoistočne Evrope. Naime Bosna i Hercegovine je država u kojoj se od 2002. godine suđenja za klevetu odvijaju isključivo u parničnom postupku. U prvu grupu spadaju još Ukrajina od 2001. godine i Gruzija koja ima slična rješenja kao i BiH. Djelimičnu dekriminalizaciju provele su Estonija 2002, Kipar 2003, i Makedonija 2004. godine. Navedena tendencija dekriminalizacija klevete i uvrede od posebne je važnosti u dokaznom postupku jer je olakšan pristup sudu putem privatno-pravne tužbe. Nadalje, prilikom svjedočenja od velike je

\footnotetext{
${ }^{3}$ Zakon o obligacionim odnosima, ("Službeni list RBiH”, br. 2/92, $13 / 93$ i 13/94)

${ }^{4}$ Opširnije o navedenoj problematici vidjeti u: Haso Tajić i Vladimir M. Simović, Komentar zakona o obligacionim odnosima, Sarajevo, 2006. godine, str. 189-192.
} 
važnosti pomenuta pragmatička analiza upotrijebljenih termina koje čine meritum privatno-pravne zaštite ličnosti gdje tužilac može tražiti naknadu štete zbog pretrpljene ,duševne boli“ iskazane u novčanom obliku zbog nanošenja materijalne i nematerijalne štete.

\subsection{Pregled država koje su dosad dekriminalizirale klevetu}

U posljednje dvije decenije nije zabilježen nijedan slučaj osude novinara i urednika na kaznu zatvora u bilo koju zemlju EU osim u Poljskoj i Mađarskoj prije njihovog ulaska u EU (novinari $u$ međuvremenu pomilovani), ali je bilo nekoliko slučajeva osude uglavnom simbolične novčane kazne. Sudska praksa pokazuje da se u ovim zemljama za klevetu uglavnom sudi u parničnom (civilnom) postupku u procentu većem i od 95 posto. Tužbeni zahtjevi su uvijek novčani u vidu većih ili manjih novčanih obeštećenja za nanošenje materijalne i nematerijalne štete. ${ }^{5}$

Specifičnost djelimične dekriminalizacije zaslužuje dodatna objašnjenja za svaku zemlju. Na Kipru je kleveta ostala u krivičnom zakonu isključivo za zaštitu stranih država, najviših stranih dužnosnika i za pripadnike Nacionalne garde. U Estoniji se sudi u krivičnom postupku samo ako je u pitanju zaštita domaćih državnika. U Makedoniji su ukinute samo minimalne novčane i zatvorske kazne, a zadržane maksimalne (do tri godine zatvora), ali je ukinuta zaštita za državne funkcionere. ${ }^{6}$

Svakako treba konstatovati da dekriminalizacija predstavlja trend i o tome svjedoči sudska praksa visoko razvijenih zemalja, kao i činjenica da je veći broj novoprimljenih država članica Vijeća Evrope uveliko započelo zakonodavnu reformu i najavio potpunu ili djelimičnu dekriminalizaciju klevete u skladu s preporukama Vijeća Evrope i Evropskog suda za zaštitu ljudskih prava.

\footnotetext{
${ }^{5}$ Opširnije o problematici osude novinara vidjeti:

http://www.netnovinar.org/netnovinar/dsp_page.cfm?articleid=3482\&urlsectionid=1 069\&specilasection=art_full-68k (posljednji put pregledano 8. 4. 2018. god.) ${ }^{6} \mathrm{http}$ ://www.netnovinar.org/netnovinar/dsp_page.cfm?articleid=3482\&urlsectionid= 1069\&specilasection=art_full-68k (posljednji put pregledano 8. 4.2018. god.)
} 
Važno je istaknuti po pitanju krivičnih sankcija da se one ne primjenjuju u praksi, ali sankcije su same po sebi realnost i one postoje u zakonima. Kazne zatvora su u rasponu od tri mjeseca do sedam godina, premda se u većini slučajeva odmjevaraju do dvije godine. Najveće kazne zatvora predviđene su u zakonima Moldavija ( 7 godina), Slovačke ( 5 godina) i Turske (4 godine). Krivični postupci protiv novinara, prema izvještaju Vijeća Evrope, česti su u Moldaviji, Rumuniji, Srbiji i Crnoj Gori, Hrvatskoj, Litvaniji dr. Postoje i duže zatvorske kazne od gore navedenih. U Krivičnom zakonu u Norveškoj predviđena je kazna zatvora i do 21 godinu zatvora za zaštitu kraljevske obitelji. Za isto krivično djelo klevete kraljevske obitelji u Nizozemskoj predviđena je kazna zatvora i do 5 godina. U Poljskoj je predviđena kazna zatvora i do 10 godina u slučaju javne uvrede: poljske policije, Republike Poljske, njenog političkog sistema i najviših državnih organa. ${ }^{7}$

\subsection{Sažet pregled rješenja i prakse u svijetu s posebnim težištem na evropsku pravnu tradiciju}

Tri zemlje posjeduju ustavnu zaštitu reputacije ličnosti, predstavljenu u formulaciji čast i ugled: SAD, Švedska i Njemačka. Švedska s pravom slovi za rodonačelnika „slobode štampe“ ili kao preteča demokratskih procesa u svijetu. Ima poseban akt o slobodi štampe (Freedom of the Press Act) koji je integralan dio Ustava. Uz ustavni osnov doneseni su zakoni o kleveti i uvredi. U većini zapadnih zemalja kleveta i uvreda se tretiraju dvojako: kao krivično djelo i kao građanski prijestup. U prvom slučaju predviđene su i kazne zatvora, u drugom slučaju pretežno novčane kazne za slučaj nematerijalne štete. Ako su uvreda i kleveta formulisane kao krivično djelo i ako je utvrđena i materijalna šteta, onda se uz zatvorsku kaznu određuje i novčano obeštećenje. ${ }^{8}$

U Austriji nema kompenzacije za nematerijalnu štetu. Lijek je u pravilu javno objavljivanje izvinjenja. Za austrijsku praksu je bitno kako tužitelj treba dokazati krivicu tuženog što nije slučaj u zemljama rigidnog (zapadnog) pravnog sistema. Austrija je imala svoju katarzu u

\footnotetext{
${ }^{7} \mathrm{http}: / /$ www.mediaonline.ba/ba/print.asp?ID=239-17k-( posljednji put pregledano 8 . 4. 2018. godine)

${ }^{8} \mathrm{http}: / /$ www.mediaonline.ba/ba/print.asp?ID=239-17k-( posljednji put pregledano 8 . 4. 2018. godine)
} 
već čuvenom slučaju Lingens protiv Austrije iz 1986. godine kada je Evropski sud za ljudska prava osporio presudu domaćeg suda $\mathrm{u}$ predmetu novinara koji je navodno vrijeđao političara s nacističkom prošlošću. Strazburški organi pridaju puno važnosti slobodi štampe. Dužnost štampe je da prenosi informacije i ideje o političkim pitanjima kao i svim onim iz drugih oblasti javnih interesa. Ovaj naglasak na javnom interesu se odražava u praksi posebno u vezi s ograničenjima slobode izražavanja. ${ }^{9}$

Prema francuskom zakonodavstvu, klevetanje predstavlja i krivično djelo i građanski prijestup. Francuska ne poznaje institut savjeta/vijeća za štampu niti ostale mehanizme samoregulacije medija. Određenu ulogu medijatora $\mathrm{u}$ eventualnim sporovima imaju organizovane $\mathrm{i}$ uticajne novinarske asocijacije. Zanimljivo je da nije bilo zahtjeva za takvo tijelo od strane predstavnika medija. Ovo se uglavnom objašnjava činjenicom da Francuska ima koherentan, efikasan i pouzdan pravni sistem. Na federalnom nivou ne postoje zakoni koji se ekskluzivno bave medijima, a to znači da mediji ne uživaju poseban tretman, već se klevetom posredstvom medija bave opći zakoni. Klevetanje je dovedeno $\mathrm{u}$ usku korelaciju $\mathrm{s}$ privatnošću, koja je često predimenzionirana. ${ }^{10}$

Zanimljivo je kako u Austriji i Kanadi novinari ne uživaju pravnu zaštitu kao njihove kolege u Evropi. U predmetima klevete i uvrede, novinari mogu biti novčano kažnjeni, ili čak služiti i kaznu zatvora ako odbiju otkriti izvor informacije i zaštitu privatnosti, a u tijesnoj su vezi s uvredom i klevetom.

\subsection{Odnos krivičnopravne i građanskopravne odgovornosti}

Postoje uistinu svi razlozi za premještanje medijske odgovornosti prema građanima $\mathrm{s}$ krivičnopravnog na privatnopravni (građanskopravni) teren. Proces koji je u tom smislu u toku sam po sebi je nezaustavljiv. Valja ipak priznati da će krivičnopravna odgovornost, mada i ovako bitno reducirana, još dugo koegzistirati $\mathrm{s}$

\footnotetext{
${ }^{9}$ P. van Dijk, G. J. H. van Hoof, Teorija I praksa Evropske konvencije o ljudskim pravima, Sarajevo, 2001. str. 539.

${ }^{10}$ Opširnije o navedenoj problematici vidjeti u: P.van Dijk, G. J. H.van Hoof, Teorija i praksa Evropske konvencije o ljudskim pravima, Sarajevo, 2001. str. 540.
} 
građanskopravnom. Ona, uostalom, još uvijek postoji i tamo gdje je najviše reducirana $\mathrm{u}$ SAD. ${ }^{11}$

$\mathrm{Na}$ taj način će i u medijskom pravu dio problematike biti regulisan $\mathrm{u}$ domenu krivičnog prava. To je ujedno i razlog koji nameće nužnost pravilnog razgraničenja između ovih oblika odgovornosti. Valja, prvo, zapaziti da u svijetu preteže (gotovo isključivo) krivična odgovornost medija samo kao dolozna odgovornost, tj. odgovornost za namjerno izazivanje odredene štetne posljedice. Ona kulpozna (nehajna) koja je i inače iznimka u krivičnom pravu, u medijskoj se sferi potpuno napušta. U građansko-medijskom pravu nužna je kulpozna odgovornost medija. Najveći broj zadiranja u ličnu sferu ljudi događa se upravo nehajno, bez namjere. Zato bi uz eventualno postojanje samo dolozne odgovornosti i u civilu najveći broj prekršitelja tuđih prava ličnosti i ostao bez ikakve pravne sankcije. Dolozna i kulpozna odgovornost su ovdje izjednačene. $^{12}$

Nužno je u ovom kontekstu istaknuti da postoje i druge razlike. U krivičnom pravu se krivnja dokazuje. Osnovni postulat krivičnog prava definisan je u kontekstu: "Niko ne smije biti osuđen dok mu se krivnja ne dokaže." U građanskom pravu, medutim, odgovornost je bazirana na presumpciji krivnje u velikom broju pravnih sistema. Građanskopravna odgovornost $u$ tom pogledu pruža pravnu zaštitu oštećenoj osobi, a pravno gledano "penalizira" štetnika. Nadalje u krivičnom pravu subjekt krivične odgovornosti je u pravilu fizička osoba, a samo je iznimno i pravna osoba. Na području medijskog prava tu je situacija specifična. Naime, najvećim dijelom (u domenu krivične i građanske odgovornosti) odgovara samo pravna osoba (izdavač). Međutim, navedena tendencija je u razvoju i nailazi na još mnogo različitih prepreka.

Izvjesne razlike postoje i u proceduralnom smislu. Ako samo izdavač može biti optužen, novinar će tada biti svjedok i treba njegovu poziciju svjedoka pokriti nekim specificnim oblikom blagodati nesvjedočenja. Neke posebnosti za analizu odnosa građanskopravne i krivičnopravne

\footnotetext{
${ }^{11}$ http://www.pravri.hr/hr/zbornik/v28_1/08_radolovic.pdf (posljednji put pregledano 21. 4. 2018. godine)

12 Opširnije vidjeti: http://www.pravri.hr/hr/zbornik/v28_1/08_radolovic.pdf (posljednji put pregledano 21. 4. 2018. godine)
} 
odgovornosti medija pokazuju neka specifična, nova sredstva medija kao što je npr. internet. Tu je objekt napada još više gospodarski (imovinski) interes određenih subjekata koji može biti povrijeđen lažnim sadržajem web-stranice neke konkurentske firme. ${ }^{13}$

\section{ZAKLJUČAK}

U zaključnoj kontekstualizaciji problema nužno je istaknuti da se u fokus interesovanja navedenog rada stavljaju države koje su dosad dekriminalizirale klevetu, dakle države koje su 'smjestile' institut „klevete“ i ,uvrede“ u domen građansko-pravne odgovornosti gdje je olakšan pristup sudu jer stranke privatno-pravnom tužbom mogu potraživati svoja prava i novčanu naknadu za pretrpljenu „duševnu bol““ što je zakonom zaštićena kategorija. Nadalje u dokaznom postuku od velike je važnosti gore pomenuta pragmatička analiza upotrijebljenih termina što je od velike važnosti prilikom dokazivanja i svjedočenja. Potom se nameće pitanje - da li se ove tendencije u građanskom pravu, naknade štete u novčanom obliku za materijalnu i nematerijalnu štetu, trebaju u potpunosti prenijeti i na prostor instituta „uvrede“ i ,klevete“, odnosno, u krajnjoj instanci i u domen medijske privatne odgovornosti? Odgovor na gore postavljeno pitanje može se formulisati kao jedna kategorija „pro futuro“ zakonskog rješenja u smislu jačanja medijskog prava kao jedne posebne kategorije gdje se i novinarima treba pružiti odgovarajuća pravna zaštita koja još uvijek nije dovoljno ,zaživjela“ u zakonodavstvu Bosne i Hercegovine, mada se vrlo često govori o ljudskim pravima i zaštiti prava ličnosti kao najvažnijom kategorijom.

\section{LITERATURA}

1. Buergenthal Thomas, (1998) Međunarodna ljudska prava, Magistrat, Sarajevo.

2. Ćato Muradif, (2005) Evropska civilizacija, Fojnica.

3. Edward Hall, (1959) The silent language, New York.

4. Fahira Fejzić, (2005) Medijska globalizacija svijeta, Sarajevo.

${ }^{13}$ Nataša Ružic, Zakonska ograničenja ili sloboda izražavanja na internetu?, Sveučilište Podgorica, 2008 godine, str. 101. 
5. George Yule, (1996) Definicije i pozadina pragmatike te deiksija $i$ udaljenost, Oxford University Press.

6. Harland Christopher, (2003) Komentar Evropske konvencije o ljudskim pravima: Prema praksi u BiH i Strazburgu, Sarajevo.

7. Haso Tajić i Vladimir M. Simović, (2006) Komentar zakona o obligacionim odnosima(četvrt vijeka sudske prakse izbor sudskih odluka od 1980.do 2005. godine), Sarajevo.

8. Jack Donnelly, (1999) Međunarodna ljudska prava, Sarajevo.

9. Lamza-Maronić, M. i Glavaš, J. (2008) Poslovno komuniciranje, Osijek.

10. McNeill, D. (Ed.), (2004) Language and gesture, New York.

11. Michael Kinczik i Astrid Zipfel, (1998) Uvod u publicističku znanost $i$ komunikaciji, Beograd.

12. Milutin M. Nenadović, (2010) Vještina komuniciranja, Beograd.

13. Mehmed Halilović i Amer Džihana, (2012) Medijsko pravo u Bosni i Hercegovini, Sarajevo.

14. Morris, D. Peoplewatching, (2002) Guide to the body language, London.

15. P.van Dijk, G. H. J. van Hoof, (2001) Teorija i praksa Evropske konvencije o ljudskim pravima, Sarajevo.

16. Petzold Herbert, Hugh Chetwynd, Osmanagić Nedim, Sevima SaliTerzić (2001) Izvod iz prakse Evropskog suda za ljudska prava 2, Sarajevo.

17. Roth, Winfried, (2004) Priručnik semiotike, Zagreb.

18. Rijavec, M. i Miljković D. (2002) Neverbalna komunikacija-Jezik koji svi govorimo, Zagreb.

19. Sadiković Ćazim, (2001) Evropsko pravo, Magistrat, Sarajevo.

20. Sali Sevima i Terzić Zlatan, (1996) Međunarodni dokumenti o ljudskim pravima, Pravni centar.

21. Tvrtko Prćić, (1997) Semantika i pragmatika reči, Novi Sad.

\section{Web-portali:}

22. 1.http://www.netnovinar.org/netnovinar/dsp_page.cfm?articleid=3482 \&urlsectionit $=1069 \&$ specialsection=ART_FULL-68k-

23. 2.http://www.mediaonline.ba./ba/print.asp?ID $=239-17 \mathrm{k}-$

24. 3.http://www.nuns.org.yu/zakoni/pregled.jsp-133k- 
25. 4.http://www.netnovinar.org/netnovinar/dsp_page.cfm?articleid=2075 \&urlsectionid $=1069 \&$ specialsecton=ART_FULL-60k-

26. 5.http://www.netnovinar.org/.../dsp_page.cfm?articleid=2074\&specials ection=ART_FULL\&pageid $=453 \&$ PSID $=4856-59 \mathrm{k}-$ 


\title{
COMPARATIVE AND PRAGMATIC ANALYSIS OF INSULT AND DEFAMATION AND THEIR LEGAL REFLECTIONS
}

\author{
PhD Hatidže Burnić, Islamic Faculty of Pedagogy \\ University of Bihać \\ E-mail:hatidze_b@hotmail.com \\ Anita Ramulić Mujkić, Islamic Faculty of Pedagogy \\ University of Bihać \\ E-mail:anita_ramulic@yahoo.com
}

\section{Abstract}

The honor and reputation of the personality are one of the significant social values. If we prevent individuals from protecting their personal dignity and reputation, we are essentially encroaching on basic human rights. Bosnia and Herzegovina has decriminalized defamation and insult through the adoption of the Law on Defamation. The basic features of crimes against honor and reputation were determined by criminal legislation in the early 19th century, when clearer boundaries between defamation and insult were established. Specifically, a number of theorists believe that punishment for defamation and insult in this way is uncivilized and undemocratic behavior that threatens the freedom of the media and ultimately violates basic human rights and freedoms. States should therefore approach democratic standards through the decriminalization of slander and insult. It is for the aforementioned reason that the paper deals with comparative analysis of defamation and insult legislation as well as its legal reflections. Furthermore, in practice, there are major problems in proving insult and defamation, so it is necessary to approach a pragmatic analysis of the terms used in the context of defamation. Namely, the defendant can defend himself by stating that "he did not mean it in that way", ie that he did not intend to achieve the stated legal consequence by his statement, and therefore we set out to establish the pragmatic goals of insult and defamation and their legal reflection.

Keywords: insult and defamation, decriminalization, comparative analysis, pragmatic analysis. 
الدكتور المحاضر سيدة خديجة بورنيتش بيث

جامعة بيهاتش

كلية التربية الإسلامية

E-mail:hatidze_b@hotmail.com

الأستاذة أنيتا رامولَيتش مويكيتش

جامعة بيهاتش

كلية التربية الإسلامية

E-mail:anita_ramulic@yahoo.com

التحليل المقارن والواقعي للشتم والافتراء وانعكاساتها القانونية

\section{الملخص}

شرف الإنسان وسمعته واحدة من القيم الاجتماعية الهامة، ولو منعنا الأفراد من حماية كرامتهم وسمعتهم الشخصية فنكون قد تعدينا بذلك على حقوقهم الإنسان الإنسانية الأساسية. لقد ألغت البوسنة والهرسك تجريم الشتم والافتراء من خلال اعتماد القانون المعني بالشتم والافتراء.

تم تحديد السمات الأساسية للجرائم ضد الشرف والسمعة من خلال التشريع الجنائي

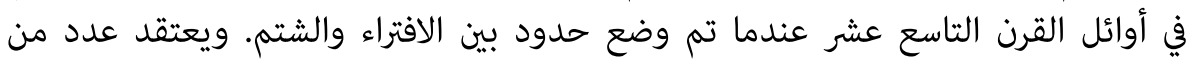

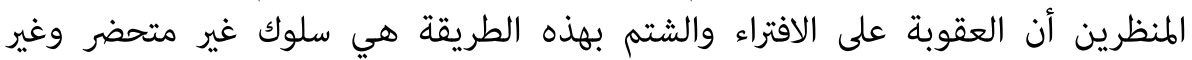

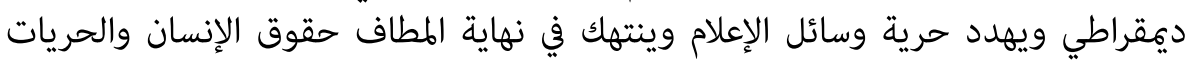

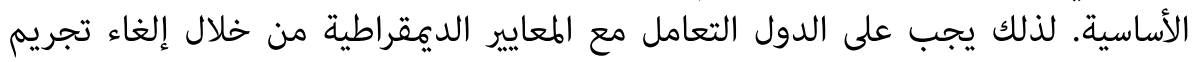

للسبب المذكور أعلاه تناولت هذه الورقة تحليلًا مقارنًا لتشريعات معنية بالافتراء

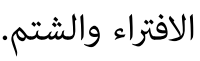
والشتم وكذلك انعكاساتها القانونية. علاوة على ذلك هناك - في الممارسة العملية - مشاكل

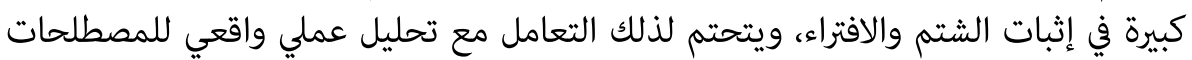

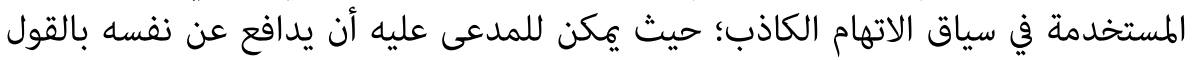

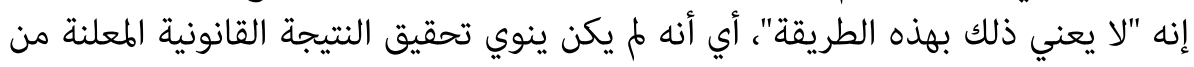

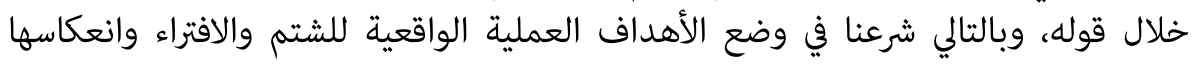
القانوني.

الكلمات المفتاحية: الشتم والافتراء، إلغاء التجريم، التحليل المقارن، التحليل العملي 